\title{
Inhalation of the Rho-kinase inhibitor Y-27632 reverses allergen-induced airway hyperresponsiveness after the early and late asthmatic reaction
}

\author{
Dedmer Schaafsma*, I Sophie T Bos, Annet B Zuidhof, Johan Zaagsma and
} Herman Meurs

Address: Department of Molecular Pharmacology, University of Groningen, Antonius Deusinglaan 1, 9713 AV Groningen, The Netherlands Email: Dedmer Schaafsma* - d.schaafsma@rug.nl; I Sophie T Bos - I.S.T.Bos@rug.nl; Annet B Zuidhof - A.B.Zuidhof@rug.nl; Johan Zaagsma - J.Zaagsma@rug.nl; Herman Meurs - H.Meurs@rug.nl

* Corresponding author

Published: 26 September 2006

Respiratory Research 2006, 7:121 doi:10.1186/1465-9921-7-121
Received: 13 July 2006

Accepted: 26 September 2006

This article is available from: http://respiratory-research.com/content/7/I/I21

(C) 2006 Schaafsma et al; licensee BioMed Central Ltd.

This is an Open Access article distributed under the terms of the Creative Commons Attribution License (http://creativecommons.org/licenses/by/2.0), which permits unrestricted use, distribution, and reproduction in any medium, provided the original work is properly cited.

\begin{abstract}
Background: In guinea pigs, we have previously demonstrated that the contribution of Rho-kinase to airway responsiveness in vivo and ex vivo is enhanced after active sensitization with ovalbumin (OA). Using conscious, unrestrained OA-sensitized guina pigs, we now investigated the role of Rho-kinase in the development of airway hyperresponsiveness (AHR) after the allergen-induced early (EAR) and late asthmatic reaction (LAR) in vivo.
\end{abstract}

Methods: Histamine and $\mathrm{PGF}_{2 \alpha} \mathrm{PC}_{100}$-values (provocation concentrations causing $100 \%$ increase in pleural pressure) were assessed before OA-challenge (basal airway responsiveness) and after the OA-induced EAR ( $5 \mathrm{~h}$ after challenge) and LAR ( $23 \mathrm{~h}$ after challenge). Thirty minutes later, saline or the specific Rho-kinase inhibitor Y-27632 (5 mM, nebulizer concentration) were nebulized, after which $\mathrm{PC}_{100}$-values were reassessed.

Results: In contrast to saline, Y-27632 inhalation significantly decreased the basal responsiveness toward histamine and $\mathrm{PGF}_{2 \alpha}$ before OA-challenge, as indicated by increased $\mathrm{PC}_{100}$-values. Both after the allergen-induced EAR and LAR, AHR to histamine and $\mathrm{PGF}_{2 \alpha}$ was present, which was reversed by $Y-27632$ inhalation. Moreover, there was an increased effectiveness of Y-27632 to reduce airway responsiveness to histamine and $\mathrm{PGF}_{2 \alpha}$ after the EAR and LAR as compared to prechallenge conditions. Saline inhalations did not affect histamine or $\mathrm{PGF}_{2 \alpha} \mathrm{PC}_{100}$-values at all. Interestingly, under all conditions Y-27632 was significantly more effective in reducing airway responsiveness to $P_{G F}$ as compared to histamine. Also, there was a clear tendency $(P=0.08)$ to a more pronounced degree of $A H R$ after the EAR for $\mathrm{PGF}_{2 \alpha}$ than for histamine.

Conclusion: The results indicate that inhalation of the Rho-kinase inhibitor Y-27632 causes a considerable bronchoprotection to both histamine and $\mathrm{PGF}_{2 \alpha}$. Moreover, the results are indicative of a differential involvement of Rho-kinase in the agonist-induced airway obstruction in vivo. Increased Rho-kinase activity contributes to the allergen-induced AHR to histamine and PGF $_{2 \alpha}$ after both the EAR and the LAR, which is effectively reversed by inhalation of Y-27632. Therefore, Rho-kinase can be considered as a potential pharmacotherapeutical target in allergic asthma. 


\section{Background}

Asthma is an inflammatory airways disease characterized by airway hyperresponsiveness (AHR) to a variety of stimuli, including contractile agonists such as histamine and prostaglandin $\mathrm{F}_{2 \alpha}\left(\mathrm{PGF}_{2 \alpha}\right)$ [1-4].

Agonist-induced smooth muscle contraction is largely governed by phosphorylation of the 20kDa myosin light chain $\left(\mathrm{MLC}_{20}\right)$ [5]. $\mathrm{MLC}_{20}$ phosphorylation is initiated by an increase in intracellular $\mathrm{Ca}^{2+}$-concentration $\left(\left[\mathrm{Ca}^{2+}\right]_{\mathrm{i}}\right)$ and subsequent formation of $\mathrm{Ca}^{2+}$-calmodulin, resulting in activation of myosin light chain kinase (MLCK). The extent of $\mathrm{MLC}_{20}$ phosphorylation is determined by the balance between MLCK and myosin light chain phosphatase (MLCP) activities [6]. Recently, it has been established that contractile stimuli do not exert their effects only by increasing $\left[\mathrm{Ca}^{2+}\right]_{i}$, but also by increasing the sensitivity of the contractile apparatus to $\mathrm{Ca}^{2+}$. One of the main pathways involved in this $\mathrm{Ca}^{2+}$-sensitization is the RhoA/Rho-kinase pathway $[7,6]$. Activated Rho-kinase interferes with the equilibrium of MLCK and MLCP activities by phosphorylating and thereby inactivating the myosin binding subunit of MLCP. This leads to an augmentation of $\mathrm{MLC}_{20}$ phosphorylation and hence an elevated level of contraction at an established $\left[\mathrm{Ca}^{2+}\right]_{\mathrm{i}}[7,8]$.

In vitro studies have indicated a receptor-dependent role of Rho-kinase in agonist-induced airway smooth muscle (ASM) contraction. Thus, the potency and maximal effect of histamine-induced contraction of guinea pig tracheal smooth muscle preparations were unaffected by inhibition of Rho-kinase, whereas these parameters were strongly dependent on Rho-kinase for $\mathrm{PGF}_{2 \alpha}$-induced contraction [9]. Growth factor-induced contraction of human and guinea pig ASM preparations appeared to be almost completely dependent on Rho-kinase $[10,11]$. presumably via generation of contractile prostaglandins [11]. Thusfar, no reports have been published on a differential role for Rho-kinase in airway responsiveneness to contractile agonists in vivo.

Recently, Rho-kinase has emerged to be a potential target in airways diseases, including allergic asthma [12]. Ex vivo, it has been demonstrated that Rho/Rho-kinase-mediated $\mathrm{Ca}^{2+}$-sensitization is enhanced in acetylcholine-induced contraction of bronchial smooth muscle obtained from repeatedly allergen-challenged rats [13]. Moreover, we have recently demonstrated that active allergic sensitization (without subsequent allergen exposure) increased contractile potency of guinea pig tracheal smooth muscle preparations towards histamine and $\mathrm{PGF}_{2 \alpha}$ in a Rhokinase dependent fashion. Similarly, passive sensitization-induced nonspecific ASM hyperresponsiveness and specific allergen responsiveness in these preparations were found to be dependent on Rho-kinase as well [14].
Also in vivo, using permanently instrumented, unanaesthetized, unrestrained guinea pigs, we found that the contribution of Rho-kinase to airway responsiveness to histamine was augmented after active allergic sensitization [9]. However, the contribution of Rho-kinase to the development of AHR after the allergen-induced early (EAR) and late (LAR) asthmatic reaction in this model is presently unknown.

In the present study, using the same model, we therefore investigated the involvement of Rho-kinase in the airway responsiveneness to histamine and $\mathrm{PGF}_{2 \alpha}$ before and after the allergen-induced EAR and LAR. We demonstrate that there is a differential role of Rho-kinase in the agonistinduced airway obstructions and that inhalation of the specific Rho-kinase inhibitorY-27632 results in a strong bronchoprotection to both agonists Moreover, the results indicate that increased Rho-kinase activity contributes to allergen-induced AHR to histamine and $\mathrm{PGF}_{2 \alpha}$ after both the EAR and the LAR, which is effectively reversed by Y27632 inhalation.

\section{Methods \\ Animals}

Outbred specified pathogen-free male Dunkin Hartley guinea pigs (Harlan, Heathfield, U.K.), weighing 500-700 $\mathrm{g}$, were used in this study. The animals were actively IgEsensitized to ovalbumin (OA) as described previously [15]. In short, $0.5 \mathrm{ml}$ of an allergen solution containing $100 \mu \mathrm{g} / \mathrm{ml} \mathrm{OA}$ and $100 \mathrm{mg} / \mathrm{ml} \mathrm{Al}(\mathrm{OH})_{3}$ in saline was injected intraperitoneally, while another $0.5 \mathrm{ml}$ was divided over seven intracutaneous injection sites in the proximity of lymph nodes in the paws, lumbar regions and the neck. The animals were operated 2 weeks after sensitization and used experimentally in weeks 4 to 8 after sensitization. The animals were group-housed in individual cages in climate controlled animal quarters and given water and food ad libitum, while a 12-h on/12-h off light cycle was maintained. All protocols described in this study were approved by the University of Groningen Committee for Animal Experimentation.

\section{Measurement of airway function}

Airway function was assessed in conscious, permanently instrumented, unrestrained guinea pigs, by on-line measurement of pleural pressure $\left(\mathrm{P}_{\mathrm{pl}}\right)$ as described previously [16]. In short, a small saline-filled balloon-catheter was surgically implanted inside the thoracic cavity. The free end of the catheter was driven subcutaneously to the neck of the animal, where it was exposed and attached permanently. Via an external saline-filled canula the pleural balloon was connected to a pressure transducer (Ohmeda DTX, SpectraMed, Bilthoven, the Netherlands) and an online computer system, enabling continuous measurement of $\mathrm{P}_{\mathrm{pl}}$ changes (in $\mathrm{cm} \mathrm{H}_{2} \mathrm{O}$ ). We have previously found 
that changes in $\mathrm{P}_{\mathrm{pl}}$ are linearly correlated with changes in airway resistance and hence can be used as a sensitive index for bronchoconstriction [16].

\section{Provocation procedures}

Provocations with OA, histamine and $\mathrm{PGF}_{2 \alpha^{\prime}}$ as well as administration of Y-27632 were performed by inhalation of aerosolized solutions. Aerosols were produced by a DeVilbiss nebulizer (type 646; DeVilbiss, Somerset, PA, USA), driven by an airflow of $8 \mathrm{l} / \mathrm{min}$ and resulting in an output of $0.33 \mathrm{ml} / \mathrm{min}$. Provocations were carried out in a perspex cage (internal volume of $9 \mathrm{l}$ ) in which the guinea pigs could move freely [16]. Before the start of the experiment, the animals were habituated to the experimental conditions on two sequential days at least one week after surgery, when preoperative weight had been restored. On the first day, the animals were placed in the provocation cage unconnected to the pressure transducer. After an adaptation period of at least $30 \mathrm{~min}$, three consecutive provocations with saline were performed, each exposure lasting $3 \mathrm{~min}$ and separated by a 7 -min interval. The next day, this procedure was repeated with the animals connected to the measurement system.

On the experimental days, following the habituation procedure, OA, histamine and $\mathrm{PGF}_{2 \alpha}$ provocations were performed as described below. All provocations were preceded by an adaptation period of at least $30 \mathrm{~min}$, followed by two consecutive control provocations with saline as described above. Baseline Ppl was calculated by averaging the Ppl of the last 20 min of the adaptation period.

To assess the airway reactivity to histamine, provocations were performed with an initial $25 \mu \mathrm{g} / \mathrm{ml}$ histamine solution in saline, followed by increasing dosage steps of 25 $\mu \mathrm{g} / \mathrm{ml}$. Histamine provocations lasted $3 \mathrm{~min}$, separated by 7 min intervals. Animals were challenged until $\mathrm{P}_{\mathrm{pl}}$ was increased by more than $100 \%$ above baseline for at least 3 consecutive minutes. $\mathrm{P}_{\mathrm{pl}}$ returned to baseline value within $15 \mathrm{~min}$ after the last provocation. The provocation concentration causing a $100 \%$ increase of $\mathrm{P}_{\mathrm{pl}}\left(\mathrm{PC}_{100^{-}}\right.$ value) was derived by linear intrapolation of the concentration- $\mathrm{P}_{\mathrm{pl}}$ curve and was used as a measure for airway reactivity toward the agonist. Using the same procedure, airway reactivity to $\mathrm{PGF}_{2 \alpha}$ was determined by using increasing concentrations of 1.25, 2.5, 5, 10, 15, 20, 37.5, $50,75,100$ and $125 \mu \mathrm{g} / \mathrm{ml}$ of $\mathrm{PGF}_{2 \alpha}$ in saline, respectively. OA-provocations were performed by inhalation of increasing aerosol concentrations of 0.5 and $1.0 \mathrm{mg} / \mathrm{ml}$ $\mathrm{OA}$ in saline for $3 \mathrm{~min}$, separated by $7 \mathrm{~min}$ intervals. Allergen inhalations were discontinued when an increase in $\mathrm{P}_{\mathrm{pl}}$ of more than $100 \%$ was observed. Using these conditions, none of the animals developed anaphylactic shock after allergen provocation.

\section{Provocation protocol}

On two different occasions, separated by a one week interval, histamine or $\mathrm{PGF}_{2 \alpha} \mathrm{PC}_{100}$-values were assessed $24 \mathrm{~h}$ before OA-challenge, and at $5 \mathrm{~h}$ and $23 \mathrm{~h}$ after the OAchallenge, i.e. after the early (EAR) and late (LAR) asthmatic reaction, respectively. Thirty minutes after each histamine or $\mathrm{PGF}_{2 \alpha}$ inhalation, saline or Y-27632 (5 mM) was nebulized during $3 \mathrm{~min}$, followed by reassessment of the histamine or $\mathrm{PGF}_{2 \alpha} \mathrm{PC}_{100}$-values 30 min later. Saline and Y-27632 inhalations were alternated using a random crossover design.

\section{Data analysis}

All data represent means \pm s.e. mean from $n$ separate experiments. Statistical significance of differences was evaluated using a repeated measures one way analysis of variance (ANOVA) followed by a Holm-Sidak post-test, and significance was accepted when $P<0.05$.

\section{Chemicals}

Ovalbumin (grade III) and histamine dihydrochloride were obtained from Sigma Chemical Co. (St. Louis, MO, U.S.A.). PGF $_{2 \alpha}$ was obtained from Pharmacia and Upjohn (Puurs, Belgium) and (+)-(R)-trans-4-(1-aminoethyl)-N(4-pyridyl) cyclohexane carboxamide (Y-27632) was obtained from Tocris Cookson Ltd. (Bristol, U.K.). All other chemicals were of analytical grade.

\section{Results}

In contrast to saline (Fig. 1A), Y-27632 significantly decreased the basal responsiveness toward histamine before OA-challenge, as indicated by an increased $\mathrm{PC}_{100}$ (Fig. 1B). After the EAR, AHR had developed (Fig. 1A and $1 B)$, which was reversed by Y-27632 to the level of basal responsiveness in the absence of the Rho-kinase inhibitor (Fig. 1B). Interestingly, the AHR after the LAR was even fully reversed to the basal responsiveness in the presence of Y-27632 (Fig. 1B). Saline inhalations did not affect histamine $\mathrm{PC}_{100}$-values after the EAR and LAR (Fig. 1A).

As shown in figure $2 \mathrm{~B}$, basal responsiveness to $\mathrm{PGF}_{2 \alpha}$ was also significantly inhibited by Y-27632 inhalation to a considerable extent. The AHR after the EAR was strongly reversed by Y-27632 inhalation to a hyporesponsive level as compared to basal airway responsiveness in the absence of the Rho-kinase inhibitor $(P<0.05)$. As for histamine, Y-27632 inhalation fully reversed the AHR to $\mathrm{PGF}_{2 \alpha}$ after the LAR to the basal responsiveness as measured in the presence of Y-27632 (Fig. 2B). As with histamine, saline inhalations did not affect $\mathrm{PC}_{100}$ values for $\mathrm{PGF}_{2 \alpha}$ (Fig. 2A).

As compared to basal conditions $(1.7 \pm 0.1$-fold decrease of airway responsiveness), the effectiveness of Y-27632 to reduce the airway responsiveness to histamine after the 

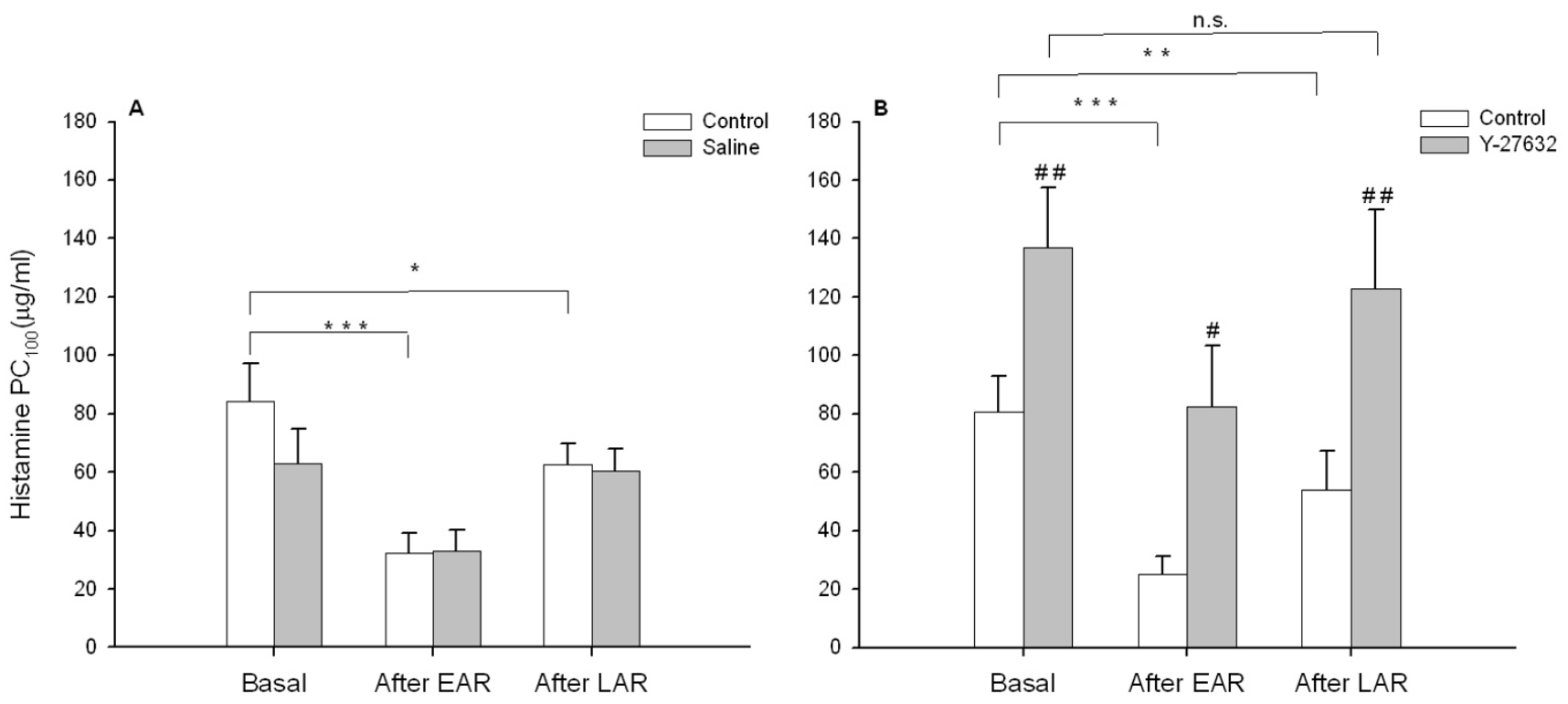

\section{Figure I}

Effects of saline (A) and Y-27632 (5 mM nebulizer concentration; B) inhalations on airway responsiveness toward histamine after the allergen-induced EAR and LAR. Data represent means \pm s.e.mean of 5 animals. $* \mathrm{P}<0.05$, $* * \mathrm{P}<0.0 \mathrm{I}$, ***P $<0.00 \mathrm{I}$ compared to basal; \#P $<0.05$, \# P $<0.0$ l compared to control.

EAR $(3.3 \pm 0.4$-fold $)$ and after the LAR $(2.3 \pm 0.1$-fold $)$ was significantly increased $(\mathrm{P}<0.05$ both; Fig. 3A). Also for $\mathrm{PGF}_{2 \alpha^{\prime}}, \mathrm{Y}-27632$ inhalation was much more effective in reducing the airway responsiveness after the EAR $(7.3 \pm$ 1.1 -fold, $\mathrm{P}<0.05)$ and the LAR $(5.6 \pm 0.7$-fold, $\mathrm{P}<0.05)$ as compared to pre-challenge conditions $(3.8 \pm 0.5$-fold decrease, Fig. 3B). Interestingly, under all conditions Y27632 was significantly more effective in reducing airway responsiveness to $\mathrm{PGF}_{2 \alpha}$ as compared to histamine, indicating that there is a receptor-dependent role for Rhokinase in airway responsiveness in vivo. In addition, we found that there is a clear tendency $(P=0.08)$ for a more pronounced degree of AHR after the EAR for $\mathrm{PGF}_{2 \alpha}(5.8 \pm$ 1.1-fold increase in airway reactivity) than for histamine (3.3 \pm 0.4 -fold increase in airway reactivity). No difference was observed in the degree of AHR after the LAR for both agonists $\left(1.7 \pm 0.2\right.$ and $1.6 \pm 0.2$ for PGF $_{2 \alpha}$ and histamine, respectively).

\section{Discussion}

In the present study, we demonstrated that inhalation of the Rho-kinase inhibitor Y-27632 causes a considerable bronchoprotection against histamine and $\mathrm{PGF}_{2 \alpha}$ under basal conditions. Moreover, we showed for the first time that in conscious, freely moving, actively OA-sensitized guinea pigs, inhalation of the Rho-kinase inhibitor Y-
27632 reverses the AHR to both agonists after the allergen-induced EAR and LAR. The results strongly indicate that an increased Rho-kinase activity is involved in the development of the allergen challenge-induced AHR, as demonstrated by an enhanced effectiveness of Y-27632 to inhibit the increased airway responsiveness to histamine and $\mathrm{PGF}_{2 \alpha^{\prime}}$ both after the EAR and the LAR.

Further investigations are warranted to reveal the exact mechanisms underlying the increased contribution of Rho-kinase to airway responsiveness after the EAR and LAR. Evidence exists that allergic sensitization by itself is already a key process in augmenting the role of Rhokinase in contractile airway responsiveness. Thus, we previously found that active allergic sensitization by itself, without subsequent allergen exposure, is sufficient to induce an enhanced role of Rho-kinase in guinea pig airway smooth muscle contraction ex vivo and airway responsiveness in vivo [9]. Also in passively sensitized guinea pig tracheal preparations, we recently found that the nonspecific hyperresponsiveness in response to histamine and methacholine was fully normalized by Rhokinase inhibition [14]. The enhanced contribution of Rho-kinase to airway responsiveness could involve increased expression of RhoA, as protein levels of this upstream activator of Rho-kinase have been reported ele- 


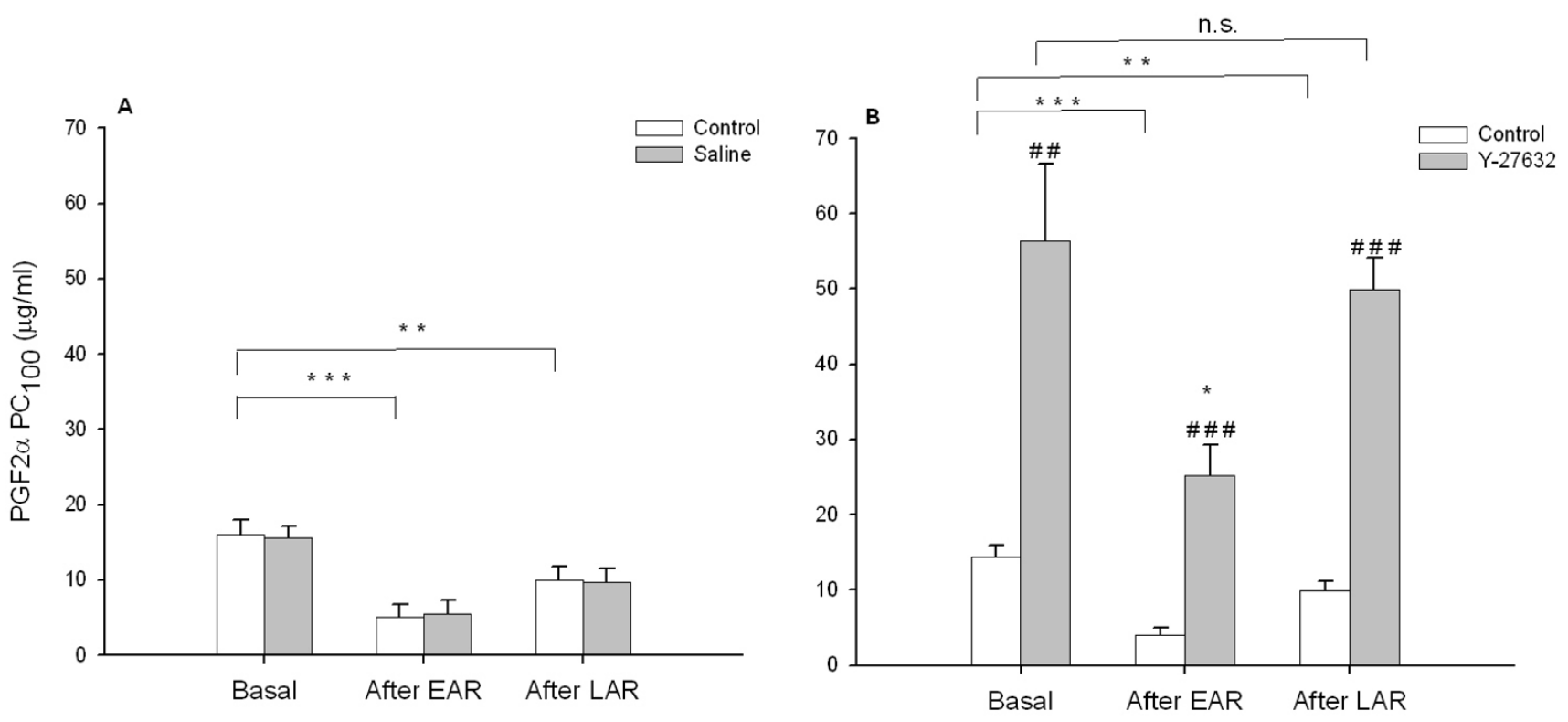

Figure 2

Effects of saline (A) and Y-27632 (5 mM nebulizer concentration; B) inhalations on airway responsiveness toward PGF $2 \alpha$ after the allergen-induced EAR and LAR. Data represent means \pm s.e.mean of 7 animals. $* \mathrm{P}<0.05$, $* * \mathrm{P}<0.0 \mathrm{I}, * * * \mathrm{P}<0.00 \mathrm{I}$ compared to basal; \#P $<0.0$ I, \#\# $\mathrm{P}<0.00$ I compared to control.

vated both after allergic sensitization in guinea pigs [9] and after repeated allergen challenge in rats [13] and mice [17]. Inflammatory cells - activated during the allergic reaction - release mediators, including prostaglandins, leukotrienes and growth factors $[18,19]$, which have been reported to be dependent on Rho-kinase for their contractile effects $[10,11]$. It can be envisaged that there is synergism in Rho-kinase activation between such mediators and the inhaled agonists, which results in a higher efficacy of Rho-kinase inhibition. In addition, Rho-kinase inhibition might have effects on airway inflammation itself, as has been suggested in a murine model of acute allergic airway inflammation. In anaesthetized mice, it was found that when Y-27632 was given intranasally prior to allergen challenge, pulmonary eosinophilia was reduced, as shown by a decreased number of eosinophils in the bronchoalveolar lavage (BAL) fluid [20]. In the same study, it was also demonstrated that intranasally administered Y27632, which was given before every allergen challenge, reduced the repeated allergen-induced increased responsiveness to intravenously applied methacholine, which might be correlated to effects on airways inflammation [20]. Also, it has been demonstrated in vitro that Y-27632 decreased the release of the Th2 cytokines IL-4 and IL-5 [21].

It has been previously reported that a differential contribution of Rho-kinase to histamine- and $\mathrm{PGF}_{2 \alpha}$-induced ASM contraction exists in vitro [9]. Fully in line with those findings, we found that such a differential role of Rhokinase also exists in vivo. Thus, under all conditions inhalation of Y-27632 was significantly more effective in reducing airway responsiveness to $\mathrm{PGF}_{2 \alpha}$ as compared to histamine. Moreover, there was a strong tendency to a more pronounced AHR after the EAR in response to $\mathrm{PGF}_{2 \alpha}$ as compared to histamine. Together with the higher efficacy by which Y-27632 inhalation reduces airway responsiveness to $\mathrm{PGF}_{2 \alpha}$ as compared to histamine, this might suggest that the severity of AHR to a certain agonist is associated with the extent to which the agonist is dependent on Rho-kinase for its contractile effect.

\section{Conclusion}

Inhalation of the Rho-kinase inhibitor Y-27632 causes a considerable bronchoprotection to histamine and $\mathrm{PGF}_{2 \alpha}$. Moreover, a differential involvement of Rho-kinase in the contractile agonist-induced airway obstructions exists in vivo. Increased Rho-kinase activity contributes to the allergen-induced AHR to histamine and $\mathrm{PGF}_{2 \alpha}$ after both the EAR and the LAR, which is effectively reversed by inhalation of Y-27632. Therefore, Rho-kinase can be considered as a potential pharmacotherapeutical target in allergic asthma.

\section{Abbreviations}

AHR, airway hyperresponsiveness; ASM, airway smooth muscle; EAR, early asthmatic reaction; LAR, late asthmatic reaction; $\mathrm{MLC}$, myosin light chain; $\mathrm{PC}_{100}$, provocation 

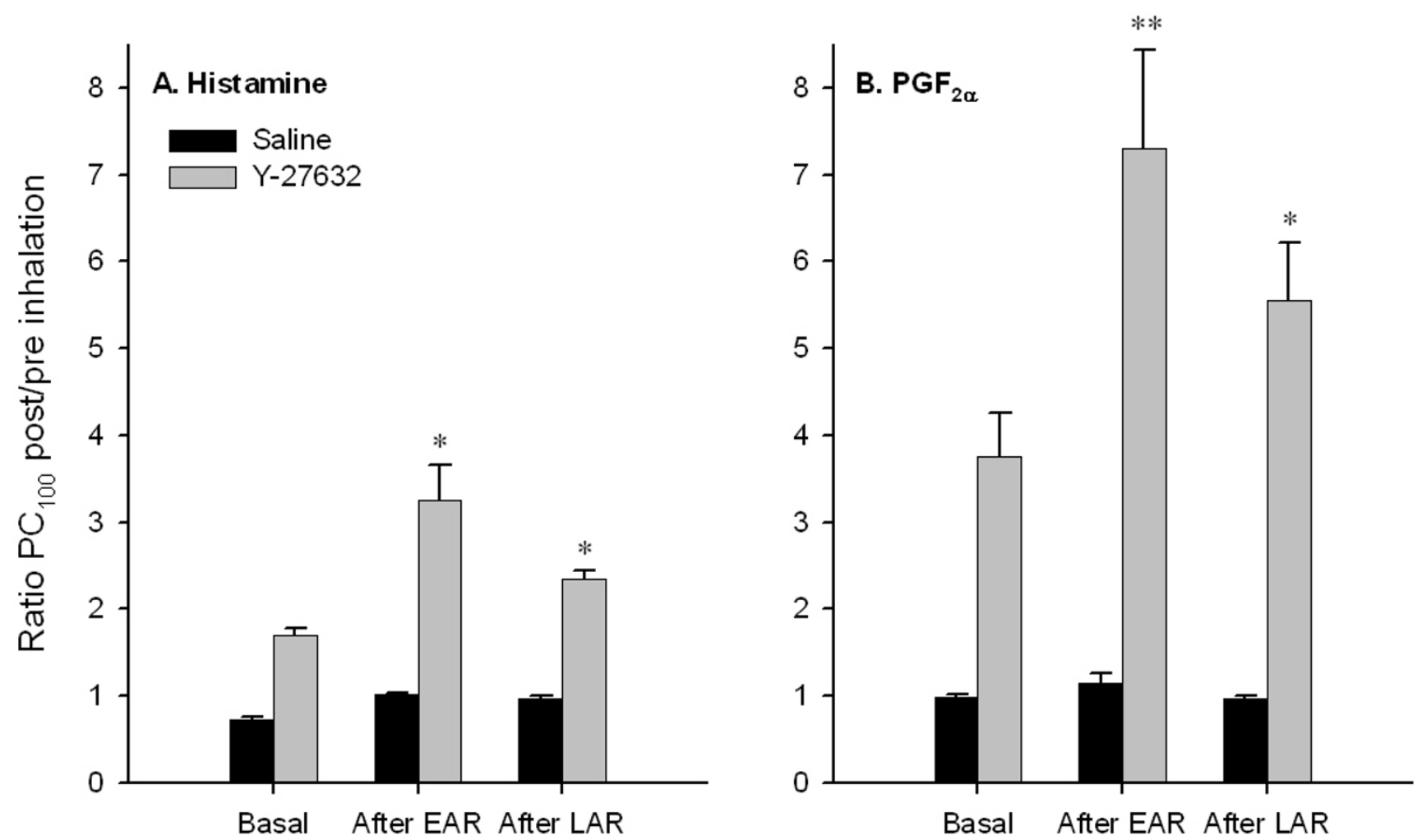

Figure 3

Effectiveness of saline and $Y-27632$ inhalations to reduce basal airway responsiveness and airway (hyper)responsiveness after the EAR and the LAR for histamine $(A)$ and $P G F_{2 \alpha}(B)$. Data are expressed as the $P C_{100}$ ratio post/pre saline or $Y-27632$ inhalation. Data represent means \pm s.e.mean of 5 (histamine) and $7\left(\mathrm{PGF}_{2 \alpha}\right)$ animals. $* \mathrm{P}<0.05 * * \mathrm{P}<0.0 \mathrm{l}$ compared to basal effectiveness.

concentration causing $100 \%$ increase in pleural pressure; $\mathrm{P}_{\mathrm{pl}^{\prime}}$ pleural pressure; $\mathrm{PGF}_{2 \alpha^{\prime}}$ prostaglandin $\mathrm{F}_{2 \alpha^{\prime}} ; \mathrm{KH}$, KrebsHenseleit; OA, ovalbumin

\section{Competing interests}

The author(s) declare that they have no competing interests.

\section{Authors' contributions}

DS designed and coordinated the study, performed a major part of the experiments, performed the statistical analysis and drafted the manuscript. ISTB and ABZ substantially assisted in performing the experiments. JZ participated in the design of the study and the interpretation of results. HM supervised the study, participated in its design and in interpretation of results as well as in the preparation of the manuscript. All authors read and approved the final manuscript.

\section{Acknowledgements}

We thank the Netherlands Asthma Foundation for financial support (grant 01.83).

\section{References}

I. Hargreave FE, O'Byrne PM, Ramsdale EH: Mediators, airway responsiveness, and asthma. I Allergy Clin Immunol 1985, 76:272-276.

2. Durham SR, Craddock CF, Cookson WO, Benson MK: Increases in airway responsiveness to histamine precede allergeninduced late asthmatic responses. J Allergy Clin Immunol 1988, 82:764-770.

3. Cockcroft DW: Nonallergic airway responsiveness. J Allergy Clin Immunol 1988, 81: III-II9.

4. Kharitonov SA, Sapienza MA, Barnes PJ, Chung KF: Prostaglandins E2 and F2alpha reduce exhaled nitric oxide in normal and asthmatic subjects irrespective of airway caliber changes. Am J Respir Crit Care Med 1998, 1 58:1374-1378.

5. Pfitzer G: Invited review: regulation of myosin phosphorylation in smooth muscle. I Appl Physiol 200 I, 9 I:497-503.

6. Somlyo AP, Somlyo AV: Ca2+ Sensitivity of Smooth Muscle and Nonmuscle Myosin II: Modulated by G Proteins, Kinases, and Myosin Phosphatase. Physiol Rev 2003, 83:1325-1358.

7. Fukata $Y$, Amano $M$, Kaibuchi K: Rho-Rho-kinase pathway in smooth muscle contraction and cytoskeletal reorganization of non-muscle cells. Trends Pharmacol Sci 200I, 22:32-39.

8. Wettschureck N, Offermanns S: Rho/Rho-kinase mediated signaling in physiology and pathophysiology. I Mol Med 2002, 80:629-638.

9. Schaafsma D, Gosens R, Bos IS, Meurs H, Zaagsma J, Nelemans SA: Allergic sensitization enhances the contribution of Rhokinase to airway smooth muscle contraction. $\mathrm{Br} J$ Pharmacol 2004, I 43:477-484. 
10. Gosens R, Schaafsma D, Grootte Bromhaar MM, Vrugt B, Zaagsma J, Meurs H, Nelemans SA: Growth factor-induced contraction of human bronchial smooth muscle is Rho-kinase-dependent. Eur J Pharmacol 2004, 494:73-76.

II. Schaafsma D, Gosens R, Bos S, Meurs H, Zaagsma J, Nelemans A: Role of contractile prostaglandins and Rho-kinase in growth factor-induced airway smooth muscle contraction. Respir Res 2005, 6:85

12. Gosens R, Schaafsma D, Nelemans SA, Halayko AJ: Rho-Kinase as a Drug Target for the Treatment of Airway Hyperresponsiveness in Asthma. Mini Rev Med Chem 2006, 6:339-348.

13. Chiba Y, Takada Y, Miyamoto S, MitsuiSaito M, Karaki H, Misawa M: Augmented acetylcholine-induced, Rho-mediated $\mathrm{Ca2}+$ sensitization of bronchial smooth muscle contraction in antigen-induced airway hyperresponsive rats. Br J Pharmacol 1999 , 127:597-600.

14. Schaafsma D, Zuidhof AB, Nelemans SA, Zaagsma J, Meurs H: Inhibition of Rho-kinase normalizes nonspecific hyperresponsiveness in passively sensitized airway smooth muscle preparations. Eur J Pharmacol 2006, 53 I: I 45-150.

15. Van Amsterdam RG, Brouwer F, Zaagsma J: Analysis of the betaadrenoceptor mediated inhibition of IgGI and IgE dependent guinea-pig anaphylactic tracheal smooth muscle contraction. Agents Actions 1989, 26:48-5I.

16. Santing RE, Meurs H, van der Mark TW, Remie R, Oosterom WC, Brouwer $F$, Zaagsma J: A novel method to assess airway function parameters in chronically instrumented, unrestrained guinea-pigs. Pulm Pharmacol 1992, 5:265-272.

17. Chiba Y, Ueno A, Shinozaki K, Takeyama H, Nakazawa S, Sakai H, Misawa M: Involvement of RhoA-mediated Ca2+ sensitization in antigen-induced bronchial smooth muscle hyperresponsiveness in mice. Respir Res 2005, 6:4.

18. McKay S, Sharma HS: Autocrine regulation of asthmatic airway inflammation: role of airway smooth muscle. Respir Res 2002, 3:II.

19. Sampson AP: The role of eosinophils and neutrophils in inflammation. Clin Exp Allergy 2000, 30 SuppI I:22-27.

20. Henry PJ, Mann TS, Goldie RG: A Rho kinase inhibitor, Y-27632 inhibits pulmonary eosinophilia, bronchoconstriction and airways hyperresponsiveness in allergic mice. Pulm Pharmacol Ther 2005, 18:67-74.

21. Aihara M, Dobashi K, lizuka K, Nakazawa T, Mori M: Comparison of effects of Y-27632 and Isoproterenol on release of cytokines from human peripheral T cells. Int Immunopharmacol 2003, 3:1619-1625.

\section{Publish with Bio Med Central and every scientist can read your work free of charge}

"BioMed Central will be the most significant development for disseminating the results of biomedical research in our lifetime. "

Sir Paul Nurse, Cancer Research UK

Your research papers will be:

- available free of charge to the entire biomedical community

- peer reviewed and published immediately upon acceptance

- cited in PubMed and archived on PubMed Central

- yours - you keep the copyright

Submit your manuscript here:

http://www.biomedcentral.com/info/publishing_adv.asp
BioMedcentral 